\section{The overtreatment of illusory May Thurner syndrome}

Paolo Zamboni, ${ }^{1}$ Claude Franceschi, ${ }^{2}$ Roberto Del Frate ${ }^{3}$

${ }^{1}$ Center for Veins and Lymphatics Diseases Regione Emilia Romagna, University Hospital of Ferrara, Cona (FE), Italy; ${ }^{2}$ Groupe Hospitalier Paris Saint-Joseph, Paris, France; ${ }^{3}$ Casa di Cura Figlie di San Camillo, Cremona, Italy

\section{Introduction}

Recently, an excellent article of van Vuuren et al. described in healthy volunteers an impressive prevalence of angiographic signs usually indicative of May Turner syndrome (MTS). ${ }^{1}$

In $80 \%$ of participants, at least two signs indicative of May-Thurner compression were seen. In $70 \%$ healthy subjects, collaterals were found to be the most typical picture of significant venous obstruction. An angiographic sign of $>50 \%$ compression was found to be an indication to stent in $55 \%$ of healthy subjects! Overtreatment should not be underestimated as previous research has already shown that only $63 \%$ of patients treated for MTS showed a clinical treatment effect. Moreover, 24\% did not show a clinical response to treatment and $14 \%$ demonstrated some fading of symptoms. ${ }^{1}$

In our clinical practice we observe the same by the means of ultrasounds, which show in asymptomatic patients left iliac vein (LIV) compression (Figure 1 left). In similar cases we slightly increase the gravitational overload and repeat the investigation with the subject in semi-settled $45^{\circ}$ position. ${ }^{2}$ The presence of an illusory MTS is followed by the relief of the compression and flow recovery in the left iliac vein (Figure 1 right). Nowadays MTS is reported by the word of mouth as a compression of the right iliac artery on the LIV. To the contrary, May and Thurner original post mortem dissection on 430 cases showed a combination of intraluminal obstacles and LIV compression in about $20 \%$ of cases. They simply hypothesized that the intraluminal obstacles, the true cause of venous obstruction, could be favorite by the compression. ${ }^{3}$ Their impressive original pictures corroborated by histology show a variety of intraluminal defects today classified as truncular venous malformations ${ }^{4}$ (Figure 2).

The original figures of the Angiology article published over 60 years ago are com- pletely mirrored by the modern IVUS, which currently may nicely depict truncular venous malformations (Figure 3). It is mandatory to improve preoperative diagnostics to avoid useless and harmful overtreatment to arrive at correct surgical indications. It is clear that illusory MTS occurs whenever the compression is reversible. The ultrasound manoeuver herein described could become an initial screening useful also to avoid more invasive or expensive diagnostic steps, demonstrating rapidly the presence of illusory MTS. To the contrary, the real MTS is related to not reversible compression and/or to associated intraluminal defects.
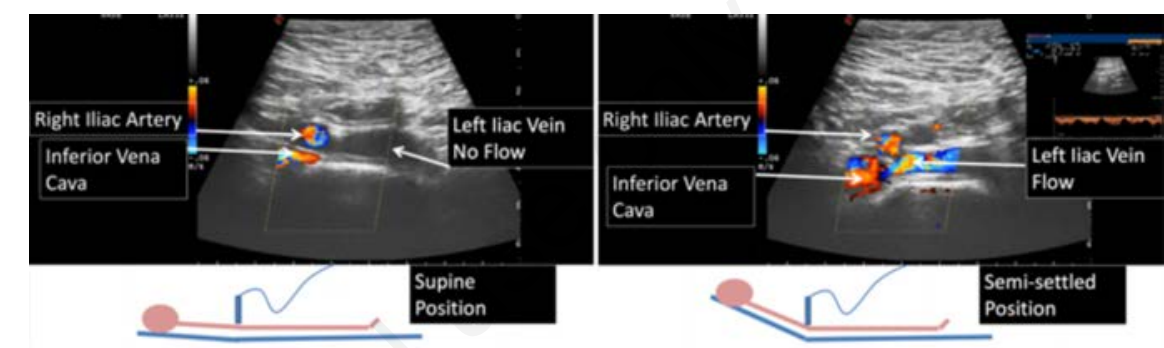

Figure 1 . The semi-settled $45^{\circ}$ position to assess the presence of illusory May Thurner syndrome at ultrasounds performed in supine position.
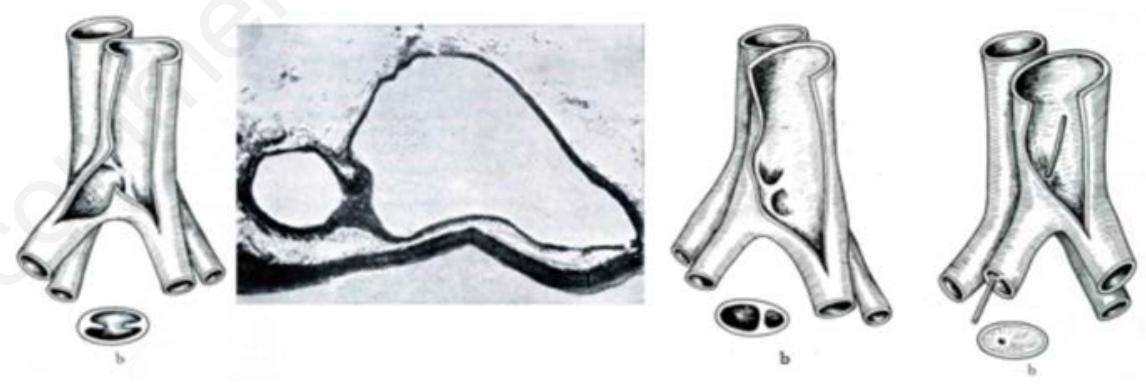

Figure 2. The original pictures and histology of intraluminal obstacles demonstrated by May and Thurner in their original post mortem study. They simply hypothesized that primary venous obstruction could be favorite by the pulsatile compression, which nowadays is considered as May Thurner syndrome.
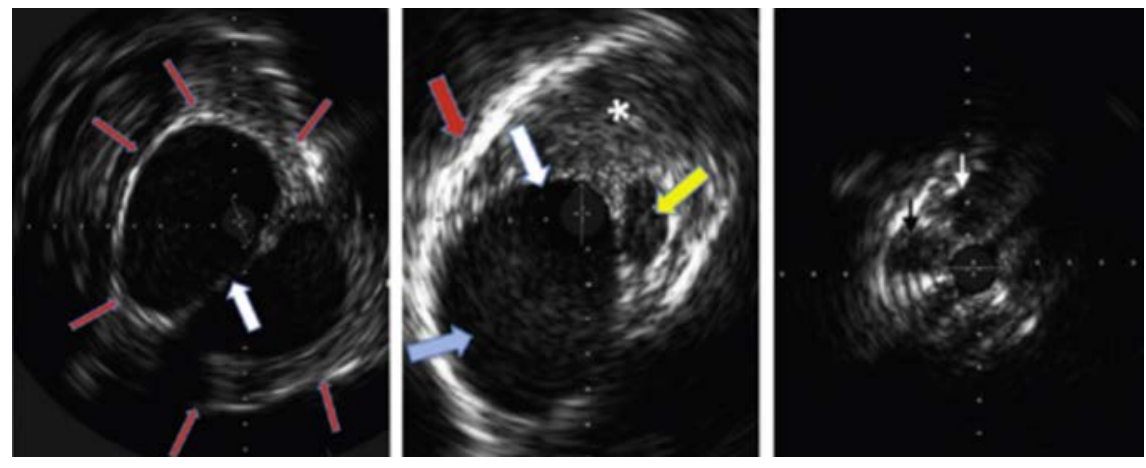

Figure 3. IVUS in case of venous truncular malformation due to intraluminal defects causing primary venous obstruction. 


\section{The need of a new diagnostic algorithm}

The article of van Vuuren et al. clearly demonstrates how the compression of the LIV is a common phenomenon, which can be very frequently observed in normal subjects. The article also demonstrates that angiographic criteria like $>50 \%$ stenosis and/or collateral circulations, which are usually used to give indication for stenting the vein, can be normally present in asymptomatic patients. It is not rare that overtreatment starts from the absence of any objective and/or subjective symptomatology. An ideal diagnostic algorithm would take into consideration patients with edema, swelling, signs and symptoms of venous hypertension reported at the level of the left lower limb. Non-invasive test should be initially considered in the patients above. We recommend the echocolorDoppler test depicted in figure 1, eventually corroborated by plethysmography either in semi-settled position and in supine, with and without leg elevation. ${ }^{4-10}$ Patients with consistent result of the non-invasive assessment could be take into consideration for angio-MR and angio-CT, eventually for invasive studies and stenting the vein.

To the contrary patients with inconsis- tent symptomatology, patients with illusory MTS at ultrasound and/or plethysmography have to be excluded from further studies.

This proposal needs of urgent studies because are completely lacking in the field in order to avoid both non-ethical over treatment of patients and increased health related cost.

\section{References}

1. van Vuuren TM, Kurstjens RLM, Wittens CHA, et al. 1llusory angiographic signs of significant lliac vein compression in healthy volunteers. Eur J Vasc Endovasc Surg 2018;56:874-9.

2. Zamboni P, Tavoni V, Sisini F, et al. Venous compliance and clinical implications Veins and Lymphatics 2018;7: 7367.

3. May R, Thurner J. The cause of the predominantly sinistral occurrence of thrombosis of the pelvic veins. Angiology 1957;8:419-27.

4. Lee BB, Baumgartner I, Berlien P, et al. Diagnosis and treatment of venous malformations. consensus document of the International Union of Phlebology (IUP): updated 2013. Int Angiol 2015;34:97-149.
5. Beggs C, Shepherd S, Zamboni P. Cerebral venous outflow resistance and interpretation of cervical plethysmography data with respect to the diagnosis of chronic cerebrospinal venous insufficiency. Phlebology 2014;29:191-9.

6. Zamboni P, Menegatti E, Conforti P, et al. Assessment of cerebral venous return by a novel plethysmography method. J Vasc Surg 2012;56:67785.e1.

7. Lattimer CR, Mendoza E, Kalodiki E. The current status of air-plethysmography in evaluating non-thrombotic iliac vein lesions. Phlebology 2018;33:3-4.

8. Lattimer CR, Mendoza E. Reappraisal of the utility of the Tilt-table in the investigation of venous disease. Eur J Vasc Endovasc Surg 2016;52:854-61.

9. Lattimer CR, Kalodiki E, Mendoza E, Geroulakos G. Regarding the value of hemodynamic measurements by air plethysmography in diagnosing venous obstruction of the lower limb. J Vasc Surg Venous Lymphat Disord 2016;4: 537.

10. Lattimer CR, Geroulakos G, Kalodiki E. Calf volume changes with venous occlusion air plethysmography in assessment of patients after deep venous thrombosis. J Vasc Surg Venous Lymphat Disord 2014;2:416-23. 